\title{
A LOGÍSTICA REVERSA COMO FERRAMENTA DA GESTÃO AMBIENTAL: UM DIAGNÓSTICO NA MICRO E PEQUENA EMPRESA
}

\author{
Késia Zoteli de Oliveira Delevedove ${ }^{1}$ \\ Rômulo Furtado Faria ${ }^{2}$ \\ Cássio Furtado Lima ${ }^{3}$ \\ Daniel Vale ${ }^{4}$
}

\section{Resumo}

O desenvolvimento sustentável exige celeridade nos processos e qualidade. A logística reversa surge para melhorar o recolhimento e recolocação de bens nos canais de distribuição, com geração de ganhos econômicos e ambientais. O objetivo deste trabalho consistiu em analisar a aplicação da logística reversa no município de Nova Venécia (ES), por meio da matriz S.W.O.T. Os dados foram obtidos via entrevista com gestores de empresas de micro e pequeno porte da cidade. Em todas as empresas analisadas observou-se uma preocupação de natureza socioambiental. No entanto, duas empresas afirmaram não ter conhecimento da legislação pertinente à problemática. Além disso, somente quatro declararam realizar a logística reversa e apenas uma apresentou uma política de conscientização do consumidor.

Palavras-chave: Matriz S.W.O.T. Resíduos. Sustentabilidade.

\section{REVERSAL LOGISTICS AS AN ENVIRONMENTAL MANAGEMENT TOOL: A DIAGNOSIS IN MICRO AND SMALL COMPANIES}

\begin{abstract}
Sustainable development requires speed in processes and quality. Reverse logistics seems to improve the collection and repositioning of goods in the distribution channels, generating economic and environmental gains. This work aims to analyze the application of reverse logistics in the municipality of Nova Venécia (ES), through the S.W.O.T. Matrix. Data were obtained through interviews with managers of micro and small companies in the city. In all the companies analyzed, a social and environmental concern was observed. However, two companies affirm they were not aware of the relevant legislation. In addition, only four declared to carry out reverse logistics and only one, presented a policy of consumer awareness.
\end{abstract}

Keywords: S.W.O.T. Matrix. Waste. Sustainability.

1 Prof. Esp. Instituto Federal do Espírito Santo (IFES), Campus Nova Venécia, Espírito Santo, Brasil. E-mail: kesia.zoteli@ifes.edu.br

2 Prof. MSc. Instituto Federal do Espírito Santo (IFES), Campus Nova Venécia, Espírito Santo, Brasil. E-mail: romulo.faria@ifes.edu.br

3 Mestrando em Ciência Florestal na Universidade Federal de Viçosa (UFV), Campus Viçosa, Minas Gerais, Brasil. E-mail: cassio.engenhariaflorestal@yahoo.com.br

4 Prof. Esp. Instituto Federal do Espírito Santo (IFES), Campus Nova Venécia, Espírito Santo, Brasil. E-mail: daniel.vale@ifes.edu.br 


\section{INTRODUÇÃO}

$\mathrm{Na}$ era primitiva o homem tirava seu sustento da natureza sem causar danos à mesma. No entanto, com o passar do tempo à humanidade passou a buscar alternativas de sobrevivência que vieram a transformar essa relação. Além da sobrevivência, o ser humano se desenvolveu e passou a obter excedente, impactando os recursos naturais, fator que provocou um aumento excessivo do consumo e, por consequência, provocou a diminuição e escassez de tais recursos em determinados locais do planeta (NEVES et al., 2016).

Segundo Magela et al. (2017), no fim do século XX, com os problemas ambientais já bem visíveis, a população percebeu a necessidade de um desenvolvimento equilibrado às questões ambientais e socioculturais. Com a crescente evolução capitalista do século XXI e, consequentemente, o aumento exponencial do consumo per capita, levantou-se uma questão difícil de ser solucionada, a geração exagerada de resíduos no país (JACINTO; ZOGAHIB, 2016).

De acordo com o relatório técnico mais recente disponível pela Associação Brasileira de Empresas de Limpeza Pública e Resíduos Especiais - ABRELPE, a geração total de resíduos sólidos urbanos (RSU) no Brasil em 2014 foi de aproximadamente 78,6 milhões de toneladas, chegando a valores de aproximadamente 1,04 kg/habitante/dia (MANNARINO, FERREIRA e GANDOLLA, 2016).

A sociedade tem um papel fundamental para que ocorra um equilíbrio entre as questões econômicas, sociais e ambientais, conforme o princípio da responsabilidade compartilhada, citada na Política Nacional de Resíduos Sólidos de 2010. No entanto, o cenário no Brasil ainda está longe de alcançar tal equilíbrio (OLIVEIRA et al., 2010). Um reflexo do aumento do poder aquisitivo dos brasileiros, desde 2003 até 2014, está relacionado com o elevado descarte de resíduos sólidos. A ONU (2015) afirmou que aproximadamente 80 mil toneladas de resíduos sólidos urbanos são descartados de forma inadequada no Brasil, correspondendo a mais de $40 \%$ do RSU coletado.

Segundo Pitelis (2013) é fundamental o equilíbrio entre os pilares: social, econômico e ambiental do chamado desenvolvimento sustentável, sendo necessária uma visão sistêmica dos gestores das organizações para promover maior sincronia entre organizações, sociedade e meio ambiente. Nesse 
contexto, Silva et al. (2015), relatam que as principais dificuldades encontradas para a melhoria da gestão ambiental eficiente são: falta de recursos financeiros, desconhecimento da legislação, entre outros. Com isso, a gestão ambiental pode ser compreendida como um conjunto de diretrizes e atividades administrativas e operacionais realizadas pela empresa para abordar problemas ambientais decorrentes da sua atuação ou para evitar que estes ocorram no futuro (HALLAK et al., 2010).

Nos anos 80, os gastos com a proteção ambiental começaram a ser vistos pelas empresas líderes não primordialmente como custos, mas sim como investimentos no futuro e, paradoxalmente, como vantagem competitiva (MARTINS, SILVA e CARNEIRO, 2017). Apesar das orientações internacionais e da crescente preocupação com o meio ambiente, o Brasil tem valores crescentes de resíduos descartados de forma inadequada, conforme já exposto pela ONU (2015). Na tentativa de reverter tais índices, o Ministério do Meio Ambiente (MMA), através da Política Nacional de Resíduos Sólidos (PNRS) de 2010, destaca a compreensão do princípio da responsabilidade compartilhada, como sendo fundamental para o sucesso do instrumento da logística reversa apresentados na Lei Federal 12.305/2010 e seu decreto 7.404/2010 (BRASIL, 2010).

Tendo em vista o desafio das organizações para o devido enquadramento nos três pilares econômico, social e ambiental - da sustentabilidade (ONU, 2017) as empresas vêm apresentando estratégias que exigem celeridade nos processos e ao mesmo tempo, a manutenção da qualidade dos seus produtos (LIMA et al., 2016).

O instrumento da logística reversa presente na PNRS apresenta um processo inverso, ou seja, objetiva realizar o fluxo do produto da origem até o consumidor final, com satisfação das suas necessidades. Enquanto a logística reversa tem o propósito de encaminhar os resíduos descartados pelo consumidor final a um tratamento adequado. Tem como objetivo garantir o recolhimento e recolocação de bens nos canais de distribuição, prolongando o tempo de vida dos materiais, gerando dessa forma ganhos econômicos e ambientais, agregando valor a um produto antes descartado na cadeia (JUNIOR et al., 2013).

Deste modo, observa-se que o instrumento da logística reversa pode ser utilizado como ferramenta da gestão para minimizar o descarte dos resíduos sólidos de forma inadequada. Os resíduos 
descartados podem ser encaminhados para reciclagem, manufatura, reutilização e, inclusive, para a liquidação do produto que não tiver mais retorno (RIVETTI et al., 2012).

Pode então se dizer que os programas que adotam a logística reversa recuperam os resíduos sólidos e os reinserem na cadeia, como matéria prima no processo, possibilitando a mitigação dos impactos ambientais e prejudiciais à saúde humana (NETO et al., 2014). A implantação da logística reversa em organizações busca contribuir com a preservação do meio ambiente e a sustentabilidade, além disso, reduzir custos através da reutilização dos resíduos e incentivar a geração de emprego por meio da reciclagem e manufatura (MANNARINO, FERREIRA e GANDOLLA, 2016).

Tendo em vista a problemática descrita este artigo objetivou apresentar a logística reversa como uma ferramenta da gestão ambiental e analisar sua execução em empresas presentes no município de Nova Venécia - ES, por meio da utilização da matriz S.W.O.T.

\section{MATERIAL E MÉTODOS}

A escolha da pesquisa se ateve ao setor comercial, que tem caráter fundamental para execução da logística reversa em cada segmento, ou seja, está relacionada à representatividade do comércio na economia da cidade. De acordo com os dados do Relatório Anual de Informações Sociais (FINDES, 2014) 47,2\% das empresas "venecianas" localizam-se no setor do comércio.

A pesquisa apresenta caráter documental e bibliográfico, de natureza aplicada, com utilização de fundamentos qualitativos, exploratórios e descritivos. Para seu desenvolvimento, foi necessário o levantamento de dados em campo, similar aos trabalhos de SILVA et al. (2017). A coleta de dados secundários ocorreu via revisão bibliográfica, realizada em artigos publicados em periódicos, apostilas, livros e, por fim, nos websites governamentais que trazem a legislação e formas ideais de atuação das empresas que se enquadram nesse perfil.

O presente trabalho foi realizado no município de Nova Venécia (Figura 1), através de entrevistas a gestores e representantes de empresas dos ramos presentes na PNRS. 


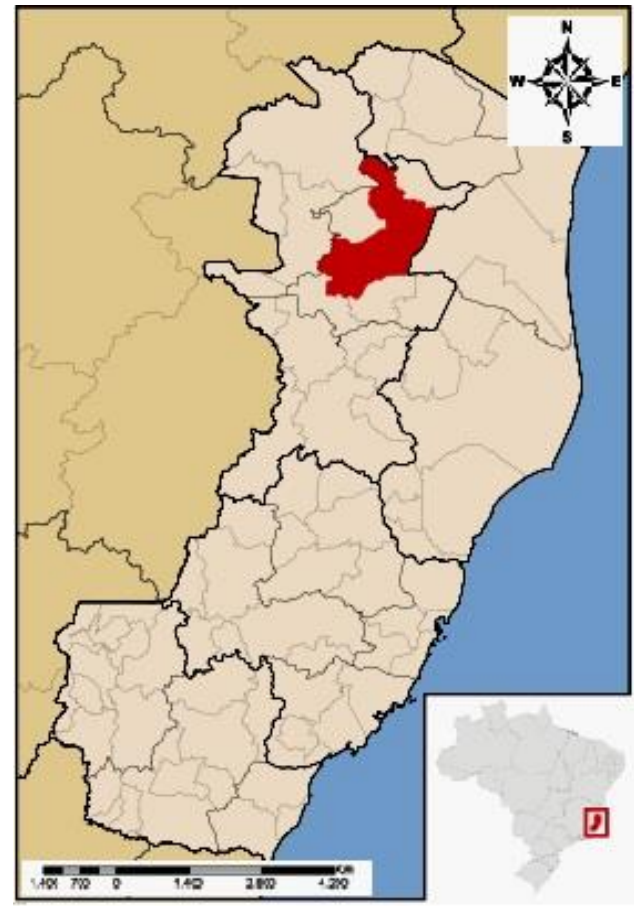

FIGURA 1 - Localização da área de estudo.

Fonte: os autores.

As entrevistas e visitas técnicas realizadas no estudo fundamentaram-se nas diretrizes da Lei Federal 12.305/2010, que institui a Política Nacional de Resíduos Sólidos - PNRS. Tomou-se por base o artigo 33, que aborda a exigência, de estruturar e implementar os sistemas de logística reversa para os fabricantes, importadores, distribuidores e comerciantes dos seguintes produtos:

1. Agrotóxicos, seus resíduos e embalagens;

2. Pilhas e baterias;

3. Óleos lubrificantes, seus resíduos e embalagens;

4. Pneus;

5. Lâmpadas fluorescentes, de vapor de sódio e mercúrio e de luz mista;

6. Produtos eletrônicos e seus componentes. 
Para a coleta de dados primários, utilizou-se entrevistas com representantes e comerciantes de cada um dos seis segmentos de produtos apresentados pela PNRS, fato que possibilitou melhor compreensão quanto às facilidades e dificuldades que as empresas enfrentam ao proceder de acordo com a legislação.

Com a execução das ações nessa escala tornou-se possível identificar o interesse e as demandas de cada segmento e particularidades presentes nas empresas. Através do check list aplicado averiguouse a preocupação dos representantes das instituições com as questões sociais e ambientais, tendo em vista que os produtos geram resíduos poluentes nos locais do município onde são comercializados.

Para o levantamento de campo, foi selecionado uma empresa comercial de cada grupo dos produtos supracitados, a fim de realizar as visitas técnicas e análises ad hoc, com especialistas do Instituto Federal de Educação, Ciência e Tecnologia do Espírito Santo, campus Nova Venécia. Considerando as questões éticas, com intuito de preservar a integridade das empresas e entrevistados, não foram divulgados imagens e nomes conforme o Termo de Anuência.

Os dados obtidos foram interpolados em modelo de matriz S.W.O.T. Segundo Carvalho et al. (2014), essa é uma importante ferramenta da gestão estratégica, onde as informações sobre o fenômeno analisado se encontram transversalizadas, para que se tenha um melhor diagnóstico, com vistas a um panorama futuro. A nomenclatura S.W.O.T. é derivada do inglês formado, pelas palavras Strength, Weakness, Opportunities and Threats, traduzido por forças, fraquezas, oportunidades e ameaças. A sua função primordial é possibilitar a escolha de uma estratégia adequada, a partir de uma avaliação crítica dos ambientes interno e externo da empresa. A exposição qualitativa dos resultados via matriz S.W.O.T., conforme metodologia de NiNIIEDERWIESER et al. (2016), possibilitou a inferência de ações técnicas fundamentais para planejamento estratégico das empresas visitadas. Devido a sua simplicidade pode ser utilizada para qualquer tipo de análise de cenário futuro.

\section{RESULTADOS E DISCUSSÃO}

Através das visitas técnicas concluiu que é insatisfatório o volume de resíduos recuperados nos diferentes grupos de seguimentos de resíduos estudados. A má ou a não utilização da logística reversa em empresas compromete o suporte técnico e econômico para a melhoria e expansão, além de dificultar 
o crescimento da economia, pois impossibilita o aumento do ciclo de vida dos materiais. As empresas se tornam competitivamente ativas ao utilizar técnicas de gestão que maximizem tanto a utilização de recursos quanto à satisfação dos clientes (MOREIRA.; GUARNIERI, 2017).

Os questionários aplicados demonstraram que apesar de conhecerem o termo "Logística Reversa", os gestores e/ou representantes das instituições desconhecem as ações que devem ser tomadas para a aplicabilidade da mesma. Esse instrumento da PNRS contribui para um processo de gestão ambiental efetivo, favorecendo o equilíbrio entre as organizações e o meio ambiente (DALEASTE et al., 2016). Segundo MANNARINO, FERREIRA e GANDOLLA (2016) a prática do processo de Logística Reversa, ainda é pouco implantada no Brasil, em especial nas micro e pequenas empresas. Tal fato foi constatado no setor do comércio no município estudado.

Com o objetivo de compreender e analisar a logística reversa em micro e pequenas empresas, na cidade de Nova Venécia ES, após a coleta dos dados, elaborou-se uma matriz S.W.O.T. para facilitar a avaliação e exposição dos dados coletados. A matriz S.W.O.T. é uma ferramenta de planejamento estratégico, a qual é muito utilizada para análise dos ambientes internos e externos das empresas. A aplicação da análise S.W.O.T. deve-se à necessidade das empresas analisarem seu posicionamento em um ambiente de permanente mudança (CARNEIRO, 2010). O Quadro 01 expõe a matriz S.W.O.T. elaborada a partir dos dados coletados no levantamento de campo.

Ao analisar o Quadro 01, observou-se que todas as seis empresas entrevistadas relataram possuir uma preocupação socioambiental e afirmaram ter ciência da geração de poluentes a partir do produto comercializado. No entanto, duas empresas representantes dos setores de pneus e lâmpadas afirmaram não ter conhecimento da legislação pertinente à gestão dos resíduos sólidos. 
QUADRO 01 - Matriz S.W.O.T. da Logística Reversa em pequena e micro empresas no município de Nova Venécia (ES).

\begin{tabular}{|c|c|c|c|c|}
\hline $\begin{array}{c}\text { Grupo } \\
\text { Temático }\end{array}$ & Pontos fortes & Pontos Fracos & Ameaças & Oportunidades \\
\hline Agrotóxicos & $\begin{array}{l}\text { - Equipe com } \\
\text { consciência } \\
\text { ambiental; } \\
\text { - Há a execução } \\
\text { da logística } \\
\text { reversa; } \\
\text { - Política de } \\
\text { conscientização } \\
\text { do consumidor. }\end{array}$ & $\begin{array}{l}\text { - Apesar do } \\
\text { incentivo, ainda há } \\
\text { dificuldade de ir até } \\
\text { o consumidor; } \\
\text { - Espaço } \\
\text { insuficiente para } \\
\text { armazenagem; } \\
\text { - Inexistência de } \\
\text { um setor específico } \\
\text { para a gestão } \\
\text { ambiental. }\end{array}$ & $\begin{array}{c}\text { - Os } \\
\text { consumidores em } \\
\text { sua grande } \\
\text { maioria não } \\
\text { fazem a } \\
\text { devolução das } \\
\text { embalagens } \\
\text { utilizadas, } \\
\text { segundo os } \\
\text { comerciantes; } \\
\text { - Fiscalização } \\
\text { insuficiente; } \\
\text { - Alto custo para } \\
\text { o transporte dos } \\
\text { resíduos. }\end{array}$ & $\begin{array}{c}\text { - Outros } \\
\text { municípios } \\
\text { possuem sistemas } \\
\text { operacionais } \\
\text { melhores no } \\
\text { controle de venda e } \\
\text { retorno de } \\
\text { produtos; } \\
\text { - Verificar em } \\
\text { outras cidades e } \\
\text { trazer para } \\
\text { implementação um } \\
\text { sistema mais } \\
\text { eficaz. }\end{array}$ \\
\hline $\begin{array}{l}\text { Pilhas e } \\
\text { Baterias }\end{array}$ & $\begin{array}{l}\text { - Equipe com } \\
\text { consciência } \\
\text { ambiental; } \\
\text { - Há a execução } \\
\text { da logística } \\
\text { reversa; } \\
\text { - Parceria firmada } \\
\text { com o fornecedor } \\
\text { de pilhas e } \\
\text { baterias para } \\
\text { coleta dos } \\
\text { resíduos gerados; }\end{array}$ & $\begin{array}{l}\text { - Não há política de } \\
\text { conscientização do } \\
\text { consumidor; } \\
\text { - Espaço físico } \\
\text { insuficiente para } \\
\text { armazenagem; } \\
\text { - Inexistência de } \\
\text { um setor específico } \\
\text { para a gestão } \\
\text { ambiental. }\end{array}$ & $\begin{array}{l}\text { - A empresa } \\
\text { coletora não tem } \\
\text { uma frequência } \\
\text { na realização da } \\
\text { coleta. }\end{array}$ & $\begin{array}{c}\text { - Retorno } \\
\text { financeiro pelas } \\
\text { baterias recolhidas. }\end{array}$ \\
\hline Pneus & $\begin{array}{l}\text { - Equipe com } \\
\text { consciência } \\
\text { ambiental; } \\
\text { - Depósito } \\
\text { adequado para } \\
\text { armazenagem. }\end{array}$ & $\begin{array}{c}\text { - Não tem } \\
\text { conhecimento da } \\
\text { legislação } \\
\text { pertinente; } \\
\text { - Não há política de } \\
\text { conscientização do } \\
\text { consumidor; } \\
\text { - Inexistência de }\end{array}$ & $\begin{array}{l}\text {-Dificuldade em } \\
\text { encontrar } \\
\text { empresas } \\
\text { especializadas no } \\
\text { descarte dos } \\
\text { pneus na região. }\end{array}$ & $\begin{array}{l}\text { - Alta demanda } \\
\text { para a reutilização } \\
\text { dos pneus em } \\
\text { jardinagem, } \\
\text { construção de } \\
\text { muros de arrimos, } \\
\text { dentre outros fins. } \\
\text { - Possibilidade de }\end{array}$ \\
\hline
\end{tabular}




\begin{tabular}{|c|c|c|c|c|}
\hline & & $\begin{array}{l}\text { um setor específico } \\
\text { para a gestão } \\
\text { ambiental. }\end{array}$ & & $\begin{array}{l}\text { retorno financeiro } \\
\text { com os pneus } \\
\text { recauchutados. }\end{array}$ \\
\hline $\begin{array}{l}\text { Óleos } \\
\text { lubrificantes }\end{array}$ & $\begin{array}{l}\text { - Equipe com } \\
\text { consciência } \\
\text { ambiental; } \\
\text { - Há execução da } \\
\text { logística reversa; } \\
\text { - Espaço físico } \\
\text { adequado para } \\
\text { armazenagem; } \\
\text { - Vendas a granel } \\
\text { do óleo (redução } \\
\text { de desperdícios) }\end{array}$ & $\begin{array}{l}\text { - Não há política de } \\
\text { conscientização do } \\
\text { consumidor; } \\
\text { - Inexistência de } \\
\text { um setor específico } \\
\text { para a gestão } \\
\text { ambiental. }\end{array}$ & $\begin{array}{l}\text { - Os produtos } \\
\text { contaminados } \\
\text { pelo óleo são } \\
\text { recolhidos por } \\
\text { uma empresa. No } \\
\text { entanto, há o } \\
\text { pagamento } \\
\text { mensal para que } \\
\text { esta coleta } \\
\text { ocorra. }\end{array}$ & $\begin{array}{c}\text { - A empresa é } \\
\text { certificada pela } \\
\text { execução da } \\
\text { logística reversa } \\
\text { destes produtos; } \\
\text { - Retorno } \\
\text { financeiro pelo } \\
\text { óleo descartado. }\end{array}$ \\
\hline $\begin{array}{c}\text { Grupo } \\
\text { Temático }\end{array}$ & Pontos fortes & Pontos Fracos & Ameaças & Oportunidades \\
\hline Lâmpadas & $\begin{array}{c}\text { - Equipe com } \\
\text { consciência } \\
\text { ambiental e social; }\end{array}$ & $\begin{array}{l}\text { - Desconhecimento } \\
\text { da legislação } \\
\text { pertinente; } \\
\text { - Desconhecimento } \\
\text { do processo de } \\
\text { logística reversa. }\end{array}$ & $\begin{array}{c}\text { - Não há empresa } \\
\text { que faça a coleta } \\
\text { dos resíduos na } \\
\text { região de acordo } \\
\text { com o } \\
\text { entrevistado. }\end{array}$ & $\begin{array}{c}\text { - Instalação de uma } \\
\text { unidade de coleta } \\
\text { desse material; } \\
\text { - Possibilidade de } \\
\text { um novo comércio } \\
\text { na região. }\end{array}$ \\
\hline $\begin{array}{l}\text { Produtos } \\
\text { eletrônicos }\end{array}$ & $\begin{array}{l}\text { - Equipe com } \\
\text { consciência } \\
\text { ambiental; }\end{array}$ & $\begin{array}{l}\text { - Ausência de } \\
\text { espaço físico para } \\
\text { armazenamento dos } \\
\text { resíduos; } \\
\text { - Não há política de } \\
\text { conscientização do } \\
\text { consumidor; } \\
\text { - Inexistência de } \\
\text { um setor específico } \\
\text { para a gestão } \\
\text { ambiental. }\end{array}$ & $\begin{array}{l}\text { - Fiscalização } \\
\text { ineficaz; } \\
\text { - Dificuldade no } \\
\text { transporte do } \\
\text { resíduo. }\end{array}$ & $\begin{array}{l}\text { - Há demanda de } \\
\text { resíduo ferroso } \\
\text { pelas empresas de } \\
\text { "ferro-velho"; } \\
\text { - Há um } \\
\text { fornecedor, no sul } \\
\text { do Brasil, que } \\
\text { recolhe os } \\
\text { resíduos. }\end{array}$ \\
\hline
\end{tabular}

Fonte: Os autores.

As outras quatro empresas afirmaram que realizam a logística reversa, mas apenas a empresa de agrotóxicos apresentou uma política de conscientização do consumidor, em consonância com a Lei Federal 11.657 de 16 de abril de 2008 que intitulou o "Dia Nacional do Campo Limpo", além da parceria com o Instituto Nacional de Processamento de Embalagens Vazias (INPEV). 
Segundo SCHNEIDER et al. (2016), os consumidores necessitam de uma conscientização para a segregação dos RSU, reinserindo o produto final como matéria prima para, após a logística reversa, ocorrer o reaproveitamento. Sem essa política de segregação de resíduos se torna inviável do ponto de vista econômico a reciclagem ou reuso de um resíduo sólido.

Como ponto fraco relatado nas visitas técnicas identificou-se como dificuldade em todos os seguimentos analisados dispor de um local adequado para o armazenamento dos resíduos. Inclusive este foi um dos requisitos apresentados por algumas empresas como motivo de não realizarem a logística reversa.

A empresa comerciante de óleo lubrificante dispõe de um espaço adequado, em conformidade com a legislação, por meio de um contrato com uma empresa que faz a coleta do óleo já utilizado e dos produtos contaminados por ele. Vale ressaltar que a empresa comerciante do óleo efetua um pagamento mensal para a empresa coletora e esta, por sua vez, paga um valor, pré-definido por tabela, pelo óleo recolhido. No caso das pilhas e baterias, um dos fornecedores de baterias dispõe de coleta remunerada das baterias e, por acordo entre eles, recolhem as pilhas para o descarte adequado.

Quando analisados os fatores externos, foi unânime a dificuldade no transporte dos resíduos, cada segmento com suas peculiaridades. No caso do agrotóxico e dos produtos contaminados pelo óleo lubrificante, os transportes destes resíduos aumentam as despesas das empresas. Em outros casos, não há conhecimento de empresas que façam o transporte e, ainda, para as pilhas e baterias, o transporte não apresenta uma periodicidade, fazendo-se necessário o armazenamento dos resíduos por um longo período.

Vale ressaltar que a PNRS apresenta a responsabilidade compartilhada no ciclo de vida dos produtos, embora a sociedade ainda não esteja ciente do seu papel neste processo. No caso dos agrotóxicos, a empresa pesquisada dispõe de um posto de coleta, mas o maior desafio encontrado foi na entrega dos resíduos por parte dos consumidores.

Observa-se que os grupos temáticos: óleos lubrificantes, pilhas e baterias possuem um retorno financeiro pelo descarte destes resíduos, com uma oportunidade de aumento no faturamento. Além disso, as empresas que atuam de forma sustentável podem utilizar este diferencial com os clientes, investindo na imagem sustentável. Porém, em nenhuma das empresas entrevistadas há a designação de 
um setor responsável pela gestão ambiental, o que pode influenciar na dificuldade das ações sustentáveis das mesmas.

Neste sentido, uma estratégia para a problemática encontrada foi a sugestão de criar um setor responsável para a gestão ambiental na organização, a fim de viabilizar a logística reversa como ferramenta de gestão. Inserido neste contexto está o descarte dos resíduos sólidos pós-consumo ou pósvenda, instrumento introduzido pela PNRS, lei $\mathrm{n}^{\circ} 12.305$, de 02 de agosto de 2010, e regulamentada pelo Decreto $\mathrm{n}^{\mathrm{o}}$ 7.404, de 23 de dezembro de 2010. Por isso todo estabelecimento que se enquadra no portfólio estabelecido na legislação supracitada deve praticar a logística reversa.

\section{CONCLUSÕES}

O presente trabalho se propôs a apresentar a logística reversa como uma ferramenta da gestão ambiental e analisar a execução da mesma por micro e pequenas empresas. Nesse sentido, ressalta-se que o município de Nova Venécia-ES necessita de uma política governamental que fomente a logística reversa para os seguimentos analisados. Os principais entraves que dificultam a gestão adequada de RSU é a ausência ou desestruturação das Unidades de Recebimento (UR's).

Apesar do levantamento de dados revelar certa preocupação socioambiental, as pesquisas no referencial teórico demonstram que essa ação por si só é ineficaz, pois é necessário utilizar o instrumento da logística reversa como uma ferramenta para a gestão ambiental eficaz no município.

Averiguou-se que alguns setores das organizações necessitam alinhar-se com as políticas ambientais para obter garantias de sustentabilidade em seus empreendimentos. Além disso, foi perceptível a cobrança do mercado consumidor, uma vez que os consumidores verdes estão ganhando espaço no mercado. No entanto, com o estudo feito por meio da pesquisa de campo, aplicado a análise da matriz S.W.O.T., observou-se que não é prática comum a existência de um setor dentro da organização para gerenciar as questões ambientais pertinentes. Portanto ressalta-se que, a empresa que trabalha com uma gestão ambiental ativa, mantêm-se informada da legislação, além de estar sempre na busca de alternativas que possam facilitar suas atividades e aumentar sua lucratividade. 


\section{REFERÊNCIAS}

ABRELPE. Associação Brasileira de Empresas de Limpeza Pública e Resíduos Especiais. Panorama dos Resíduos Sólidos no Brasil. Edição 2014. Disponível em:

<http://www.abrelpe.org.br/Panorama/panorama2014.pdf > Acesso em: 5 ago. 2016

BALLESTERO-ALVAREZ, M. E. Gestão de qualidade, produção e operações. São Paulo: Editora Atlas, 2012.

BRASIL. Lei $\mathbf{n}^{\mathbf{0}}$ 12.305, de 02 agosto de 2010. Institui a Política Nacional de Resíduos Sólidos. Disponível em: <http://www.planalto.gov.br/ccivil_03/leis/16938. htm> Acesso em: 4 jan. 2016.

BRASIL. Lei ${ }^{\circ} 11.657$ de 16 de abril de 2008. Institui o Dia Nacional do Campo Limpo. Disponível em:

<http://www.senado.leg.br/publicacoes/anais/pdf/Anais_Republica/2008/2008\%20Livro\%2015.pdf> Acesso em: 11 abr. 2017.

BRASIL. Decreto de lei $\mathbf{n}^{\mathbf{0}}$ 7.404, de 23 de dezembro de 2010. Regulamenta a Lei no 12.305, de 2 de agosto de 2010, que institui a Política Nacional de Resíduos Sólidos, cria o Comitê Interministerial da Política Nacional de Resíduos Sólidos e o Comitê Orientador para a Implantação dos Sistemas de Logística Reversa, e dá outras providências. Disponível em: <http://www.planalto.gov.br/ ccivil_03/_ato2007-2010/2010/decreto/d7404.htm> Acesso em: 4 jan. 2016.

CARNEIRO, M. F. Gestão pública: o papel do planejamento estratégico, gerenciamento de portifólio, programas e projetos e dos escritórios de projetos na modernização da gestão pública. In: BASPORT. Rio de Janeiro, 2010. Disponível em:

$<$ https://books.google.com.br/books?id=PW06BpdpdLcC\&pg=PA71\&dq=matriz+swot\&hl=ptBR\&sa= X\&ved=0ahUKEwidYjXwp3LAhVIjZAKHe1RBDwQ6AEIMzAE\#v=onepage\&q=matriz\%20swot\&f =false $>$ Acesso em: 29 fev. 2016

CARVALHO, A. R. C. de; LEAL, F. F.; DE OLIVEIRA, G. M., DE OLIVEIRA, H. A.; MENDES, H. L. F.; BEZERRA, R. C. M. Proposta de Intervenção Empresarial com Emprego da Matriz SWOT: Um Estudo na Empresa Restaurante Cheiro Verde. Revista Acta Brazilian Science, v. 1, p. 35-41, 2014.

DALEASTE, J. C.; FRANCISCO, R.; WINCK, C. A. LOGISTICA REVERSA: uma estratégia empresarial na coleta de embalagens vazias de agrotóxicos. Revista da Universidade Vale do Rio Verde, v. 14, n. 1, p. 611-628, 2016. DOI: 10.5892/ruvrd.v14i1.2615 
DEGEN, R. J. O empreendedor: empreender como opção de carreira. São Paulo: Ed. Pearson Prentice Hall, 2009.

FINDES. Caminhos para o desenvolvimento regional: Nova Venécia e região. 2014. Disponível em: <http://www.sistemafindes.org.br/download/cadernos_caminhos_para_desenvolvimento_regional_201 4/2014_cdg_nova_venecia.pdf> Acesso em: 16 fev. 2016.

HALLAK, T., STRECKER, K., GERALDO, L., OLIVEIRA, D. Effect of Steatite Waste Additions on the Physical and Mechanical Properties of Clay Composites. Journal Materials Research, v. 13, p.535-540. 2010. DOI: 10.1590/S1516-14392010000400017

IPEA. Plano Nacional de Resíduos Sólidos: Diagnóstico dos resíduos urbanos, agrosilvopastoris e a questão dos catadores. 2012. Disponível em:

<http://www.ipea.gov.br/portal/images/stories/PDFs/comunicado/120425_comunicadcomun0145.pdf> Acesso em: 15 fev. 2016.

JACINTO, A. C.; ZOGAHIB, A. L. N. Política pública de resíduos sólidos: uma análise da Lei n ${ }^{\circ}$ 12.305/201 que institui a Política Nacional de Resíduos Sólidos - PNRS, por meio dos Serviços Executados pela Secretaria Municipal de Limpeza Pública -SEMULSP no município de Manaus/AM. Revista de Administração de Roraima, v. 6, n. 2, p. 520, 2016. DOI: 10.18227/22378057rarr.v6i2.3538

JANG, Y.C., KIM, M. Management of used \& end-of-life mobile phones in Korea: A review. Journal Resources, Conservation and Recycling. v. 55, p.11-19, 2010. DOI: 10.1016/j.resconrec.2010.07.003

JUNIOR, T. A. M.; DÂNDARO, F.; AMBROSETO, G.; TABAH, J. Estudo De Caso: Coleta e Logística Reversa para Lâmpadas Fluorescentes no Município de Franca, SP. Revista Eletrônica em Gestão, Educação e Tecnologia Ambiental. v. 10, n. 10, p. 2091-2101, 2013. DOI: $10.5902 / 223611707460$

LIMA, C. F.; FARIA, R. F.; MOREIRA, R. M. G.; SANTOS, R. da S.; BERILLI, S. da S. Contribuições do Passado em Auxilio ao Futuro: Técnicas de Recuperação de Áreas Afetadas por Ruptura de Barragem de Rejeito - Um Estudo De Caso. Revista Enciclopédia Biosfera. v. 13 n. 23 ; p. 359-368. 2016. DOI: 10.18677/Enciclopedia_Biosfera_2016_031. 
MAGELA, M. M.; OLIVEIRA, E. C. de; SANTOS, R. da S.; LIMA, C. F.; LEITE, M. C. T. Análise de Tendência da Precipitação Pluvial Anual em Marilandia-ES. Revista Enciclopédia Biosfera. v. 14 n. 25, p. 70-78. 2017. DOI: 10.18677/EnciBio_2017A8

MANNARINO, C. F.; FERREIRA, J. A.; GANDOLLA, M. Contribuições para a evolução do gerenciamento de resíduos sólidos urbanos no Brasil com base na experiência Europeia. Revista Engenharia Sanitária e Ambiental, v. 21, n. 2, p. 379-385, 2016. DOI: 10.1590/S141341522016146475

MARTINS, L. O. S.; SILVA, L. T.; CARNEIRO, R. A. F. Análise da viabilidade econômica e financeira da implantação de usina de geração de energia a partir de resíduos sólidos urbanos no município de Santo Antônio de Jesus-BA. Revista Livre de Sustentabilidade e Empreendedorismo, v. 2, n. 2, p. 142-166, 2017.

MOREIRA, I. F.; GUARNIERI, P. Preferência dos Consumidores por Empresas que Implementam Práticas de Logística Reversa como Meio de Fidelização: Estudo na Indústria de Cosméticos Brasileira. Revista Gestão Industrial, v. 12, n. 4, 2017. DOI: 10.3895/gi.v12n4.5210

NETO, G. C. D.; SOUZA, M. T. S.; SILVA, D.; SILVA, L. A. Avaliação das vantagens ambientais e economicas da implantação da logística reversa no setor de vidros impressos. Revista Ambiente e Sociedade, v. 17, n. 3, p. 199-220, 2014.

NEVES, F. de O.; MENDONÇA, F. Por uma leitura geográfico-cultural dos resíduos sólidos: reflexões para o debate na Geografia. Cuadernos de Geografía. Revista Colombiana de Geografía, v. 25, n. 1, p. 153-169, 2016. DOI: 10.15446/rcdg.v25n1.43025

NIEDERWIESER, D.; BALDOMERO, H.; SZER, J.; GRATWOHL, M.; ALJURF, M.; ATSUTA, Y.; IIDA, M. Hematopoietic stem cell transplantation activity worldwide in 2012 and a SWOT analysis of the Worldwide Network for Blood and Marrow Transplantation Group including the global survey. Journal Bone marrow transplantation, v. 51, n. 6, p.778-785, 2016. DOI: 10.1038/bmt.2016.18

OlIVEIRA, A. L.; SOUZA, P. A. de; GONÇALVES, D. S.; SANTOS, A. F. dos; BENDITO, B. P. C. Análise Qualitativa dos Impactos Ambientais no Meio Abiótico em um Depósito de Resíduos Sólidos. Revista Enciclopédia Biosfera, v. 11 n. 22, p.184, 2015. DOI: 10.18677/Enciclopedia_Biosfera_2015_080 
ONU. Organizações das Nações Unidas. No Brasil, 80 mil toneladas de resíduos sólidos são descartadas de forma inadequada por dia, afirma ONU. 2015. Disponível em:

$<$ https://nacoesunidas.org/no-brasil-80-mil-toneladas-de-residuos-solidos-sao-descartados-de-formainadequada-afirma-onu/> Acesso em: 12 jan. 2016.

PITELIS, C. N. Towards a More 'Ethically Correct' Governance for Economic Sustainability. Journal of Business Ethics. Cambridge, Reino Unido. 2013. Disponível em:

<https://www.sussex.ac.uk/webteam/gateway/file.php?name= pitelisseminarpaper.pdf\&site=25>. DOI: $10.1007 / \mathrm{s} 10551-012-1616-8$

RIVETTI, L. V.; SIMONATO, D. C.; COSTA, S. O.; FIGUEIREDO, R. A. Análise documental e de percepção acerca da gestão de resíduos em um campus universitário (SP, Brasil). Revista IberoAmericana de Ciências Ambientais, Aquidabã, v. 3, n. 1, p. 98-111, 2012. Doi: 10.6008/ESS21796858.2012.001.0006.

SCHNEIDER, S.; FLACH, R. O.; WERLANG, N. B.; FAVRETTO, F. Logística Reversa: Cenário das Agroindústrias do Estado de Santa Catarina. Revista Gestão \& Sustentabilidade Ambiental, v. 5, n. 2, p. 361-381, 2016.

SILVA, M. P.; PICHARILlO, C.; DA SILVA, G. C.; DA SILVA, F. L.; GONÇALVES, J. C. Análise da Influência dos Aspectos Sociais na Percepção Ambiental da População Residente na Microbacia do Córrego do Mineirinho, Município de São Carlos-SP. Revista Eixo, v. 4, n. 2, 2017.

SILVA, W. G.; HIGUCHI, M. I. G.; FARIAS, M. S. M. Educação Ambiental na Formação Psicossocial dos Jovens. Revista Ciência e Educação. Bauru, v. 21, n. 4, 1031-1047, 2015. DOI: 10.1590/1516-731320150040015. 